\title{
Predicting native Chinese readers' perception of sentence boundaries in written Chinese
}

\author{
Kun Sun ${ }^{1 *}$, Xiaofei $\mathrm{Lu}^{2}$ \\ 1. Department of Linguistics, University of Tübingen, Tübingen, 72074, Germany \\ email: kun.sun@uni-tuebingen.de
}

2. Department of Applied Linguistics, The Pennsylvania State University, 234 Sparks Building, University

Park, PA 16802, USA

\begin{abstract}
The notion of sentencehood in Mandarin Chinese is much less well-defined than in many other languages, with a block of clauses often joined by commas without conjunctions and with the period often occurring at the end of a block of clauses to indicate meaning completeness rather than the completeness of a sentential structure. The potential factors that may affect native Chinese speakers' judgment of meaning completeness and perception of sentence boundaries have not yet been systematically examined. In light of this research gap, this study investigates the factors that may play a role in native Chinese speakers' sentence boundary perception. To this end, we conducted text re-punctuation experiments in two separate groups, a training group and a testing group, using different stimuli texts. The stimuli texts were annotated with multiple levels of linguistic information to identify potentially relevant variables that could affect the participants' sentence boundary perception. Logistic regression and the Bayesian statistical methods were applied to test the potential effects of multiple variables on the participants' responses. The logistic regression model trained on the data from the training group achieved a high level of accuracy in predicting the responses by the testing group. The model revealed a more important role of semantic information than syntactic information in the participants' sentence boundary perception. The implications of our findings for understanding the mechanisms of Chinese sentence boundaries are discussed.
\end{abstract}

Keywords: Sentence boundary perception; Re-punctuation; Corpus annotation; Logistic regression models 


\section{Introduction}

Linguists working on Chinese have placed much emphasis on syntactic differences between Chinese and Indo-European languages (Chappell \& Peyraube, 2007; Wu \& He, 2015), with many studies discussing the unique characteristics of certain Chinese syntactic constructions (e.g., the $b a$ construction and the serial verb construction) (Paul, 2008; Shi, 2000; Sun, 2018). Somewhat surprisingly, however, a more fundamental issue pertaining to the nature of basic syntactic units, i.e., the notion of sentencehood or sentence boundaries in Chinese, has not been systematically examined in comparison to the notion in other languages. Meanwhile, this notion is much less clearly defined in Chinese than in many other languages. In English written texts, for example, the boundary of a sentence generally occurs at the end a complete sentential structure, defined using largely well-established syntactic rules, and is normally punctuated using a period, question mark, or exclamation mark, with some exceptions. As such, sentence boundary perception in written texts a relatively easy task for native English speakers. While such punctuation marks are also used to mark sentence boundaries in Chinese, they do not always mark the end of a complete sentential structure in the same way they do in English. As illustrated in Example (1), multiple clauses can be joined using commas without conjunctions in Chinese texts, with the period (i.e., " $\circ "$ in Chinese) occurring at the end of the block of clauses to indicate the completeness of the meaning or idea therein rather than the completeness of a sentential structure (Lu \& Zhu, 2013:322; Huang, 1997; Xue \& Yang, 2011).

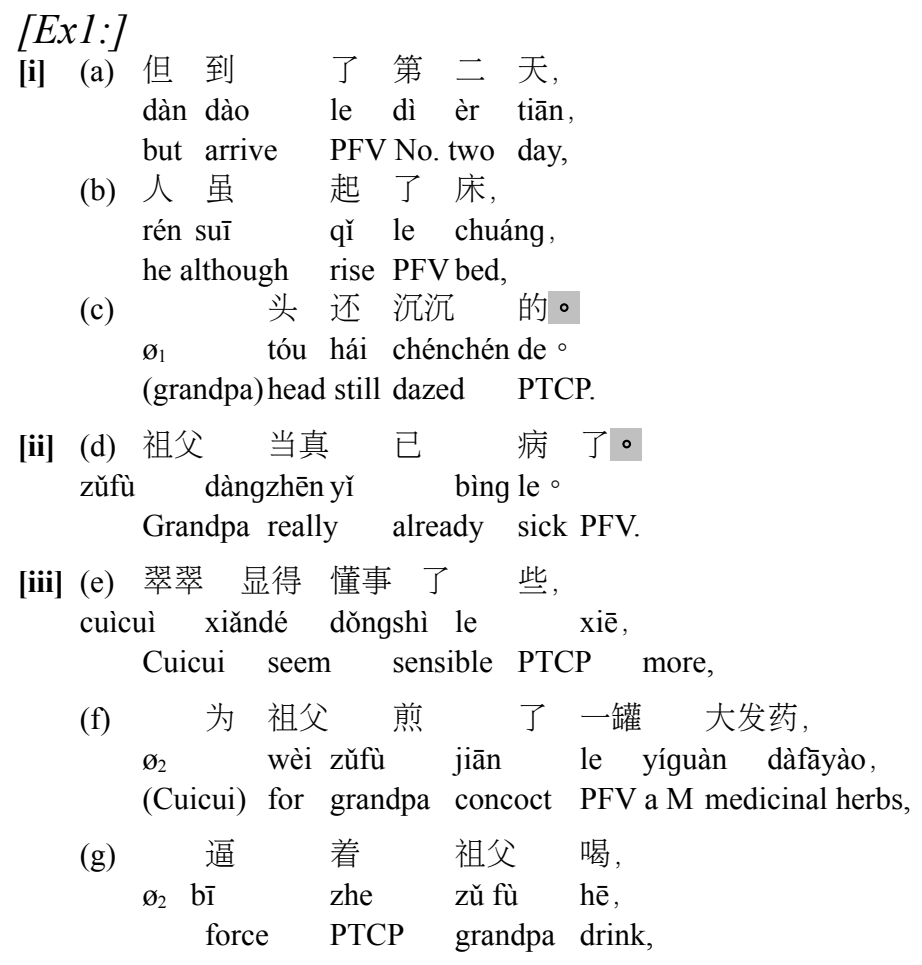



(h) 又 在 屋后
yòu zài wūhòu
also at houseback

[Translation] But on the next day, although he (grandpa) was out of bed, his head was still heavy. Grandpa was really sick. Cuicui, rising to the occasion, prepared a cooling concoction and made him take it; she then picked some garlic shoots from the vegetable garden behind the house and soaked them in rice water to make sour garlic shoots; she took care of the boats and found time to rush back home to check on grandpa whenever possible, asking how he was doing.

Example (1) contains three sentences punctuated with the period. The fact that the third sentence contains seven clauses joined with commas without conjunctions well exemplifies the point that the period in Chinese marks the completeness of a meaning or idea (as judged by the writer) rather than the end of a complete sentential structure. This point can be further illustrated by two additional facts: 1) a comma could have been used to join the first two sentences without adding any conjunction, and 2) a period could have been inserted at the end of several clauses in the third sentence, such as (e), (g) or (h) simply by replacing the empty category $\varnothing_{2}$ with a pronoun. The alternative ways to punctuate the sentences in Example (1) also indicate that the judgment of meaning completeness is a more subjective task than that of the completeness of a sentential structure, given the absence of well-defined rules.

The potential factors that affect native Chinese speakers' meaning completeness judgments and sentence boundary perception have not been systematically explored in previous research. The importance of this issue is similar to that of the issues investigated in studies of sentence boundary perception in spoken English language (Marslen-Wilson, 1975; Steinhauer \& Friederici, 2001) or word boundary segmentation in Chinese (given the lack of word boundary markers in Chinese) (Li et al., 2009; Yen et al., 2012; Ma et al., 2014). In light of the research gap, the current study sets out to determine the potential role of various syntactic and semantic factors in native Chinese speakers' sentence boundary perception. To this end, we administered a re-punctuation task to two groups of native Chinese speakers (a training group and a testing group) using two different stimuli texts. We annotated the stimuli texts for a number of syntactic, semantic and textual factors, and employed logistic regression and the Bayesian statistical methods to examine the potential effects of such factors on the participants' responses. The logistic regression model trained on the data from the training group was then used to predict the 
responses by the testing group, and the performance of the model is compared against that of a machine learning model. The two specific questions addressed in the current study are:

1) What syntactic and semantic factors may affect native Chinese readers' meaning completeness judgments and sentence boundary perception?

2) How well can a model of such factors predict native Chinese readers' sentence boundary perception?

\section{Background and Hypothesis The concept of sentence}

A sentence is a basic unit in language that can be used independently to express a complete idea or thought. In written texts in English and many other languages, sentence-final punctuation marks such as the period are used to indicate the completeness of a sentential structure, constrained largely by well-established syntactic rules (Partridege, 1998, pp. 9-13; Huddleston \& Pullum, 2002, pp. 1723-1732). For example, a simple declarative sentence in English is "a complete unit of meaning which contains a subject and a verb, followed, if necessary, by other words which make up the meaning" (Alexander, 2019, p.4), marked by a period at the end. However, as mentioned in the Introduction, the concepts of sentence and sentence boundary in Mandarin Chinese are both quite distinct from those in English. A complete sentence in written Chinese as punctuated by sentence-final punctuation represents the writer and reader's judgment of the completeness of the meaning or idea being expressed rather than of the completeness of a sentential structure. Indeed, a sentence is often described as "the completeness of an idea or meaning" (Lu, 2013, p.21) by Chinese grammarians and linguists (e.g., Huang \& Shi, 2016; Li \& Thompson, 1981). To say the least, the use of the period in Chinese is not constrained solely by syntactic rules. In particular, it frequently occurs at the end of a cluster of clauses joined by commas without conjunctions, and it is often the case that many of those clauses can function as shorter sentences either on their own or in combination with other clauses. The same rules that govern the use of the period as a sentence-final punctuation mark in English written texts thus do not fully apply in Chinese written texts.

Psycholinguistic research on sentence boundary perception in English has focused on spoken language, as the task in written language is relatively established with the existence of clear syntactic constraints. Such research has reported important effects of prosodic cues (e.g., pauses) and syntactic/semantic contextual variables on native English listeners' sentence segmentation and utterance understanding (e.g., Marslen-Wilson, 1975; Steinhauer \& Friederici, 2001). Despite the issues surrounding Chinese sentence boundaries discussed above, psycholinguistic research on Chinese sentence boundary perception has so far focused on prosodic and phonological boundaries in spoken Chinese as well (Lai et al., 2016), leaving the factors 
affecting native Chinese readers' sentence boundary perception unexplored. More broadly, a body of theoretical and experimental studies have explored the prosodic, syntactic, and semantic functions of punctuation in spoken or written texts and the ways in which punctuation may affect sentence processing and comprehension (e.g., Baron, 2001; Hirotani et al., 2006; Liu et al., 2010; Niikuni \& Muramoto, 2014; Pynte \& Kennedy, 2007; Heggie \& Wade-Woolley, 2018; Scholes \& Willis, 1990; Schou, 2007). Some researchers have also profiled the frequency distribution of punctuation marks (e.g., Kulig et al., 2017; Sun \& Wang, 2018) and developed algorithms for automatic text punctuation (e.g., Christensen et al., 2001; Liu et al. , 2006).

Based on our own observations and informed by the findings from the specific body of studies on sentence boundary perception in spoken language and the broader body of studies of the functions of punctuation marks in spoken and written texts, we hypothesize that native Chinese speakers' period use is affected by a combination of syntactic, semantic, and textual features. Our first hypothesis is that native Chinese speakers' sentence boundary perception may be influenced by syntactic factors such as the syntactic structure and length of a clause, particularly with respect to whether a single clause may be a standalone sentence. Syntactically, a single clause with either a full subject-predicate structure or a phrasal structure (e.g., a verb phrase or noun phrase) could be a standalone sentence on its own, and a single-clause sentence may be either long or short. However, it remains to be seen whether longer clauses or clauses with a full subject-predicate structure are more likely to be perceived as shorter clauses or clauses with a phrasal structure, given the difference in the amount of information encoded in such clauses.

Our second hypothesis is that the semantic relations between clauses may influence native Chinese speakers' judgments of whether the clauses are parts of the same complete meaning or different meanings. In particular, we hypothesize that two clauses with the following five semantic relations, adopted (along with their abbreviations) from the Peen Discourse Treebank (PDTB, Webber et al., 2019) and the Chinese Discourse Treebank (Zhou \& Xue, 2015), will likely be judged to be parts of the same complete meaning: 1) temporal (te), including succession, precedence, and simultaneity; 2) contingency (ce), including cause-effect, conditional, and purpose; 3) comparison (cm), including contrast and concession; 4) expansion (ex), including conjunction, succession, coordination, progression; and 5) elaboration (el), including further explanations or provisions of additional details in different categories. We also hypothesize that the use of explicit markers to indicate these semantic relations may make it more likely for the two clauses to be judged as parts of the same complete meaning.

Our third hypothesis is that certain types of semantic shifts at the textual level may affect native Chinese speakers' judgments of meaning completeness. The first type of semantic shift hypothesized to affect meaning completeness judgment is "topic shift". In Chinese, a block of clauses may form a "topic chain" when they share the same topic, which is explicitly mentioned 
in a topic clause but implicitly referred to with an empty category in several comment clauses (Li, 2004; Sun, 2019), as illustrated in the third sentence in Example (1), in which the topic "Cuicui" is explicitly mentioned in clause (e) and stays the same through the end of the topic chain. A "topic shift" occurs if a different topic arises in the next block of clauses. A block of clauses may also be put in the same sentence if their topics are different but related semantically and thematically, as illustrated in the first sentence in Example (2), in which the topics of the clauses all pertain to the natural environment. In this case, a topic shift occurs when the topic of the next block of clauses changes thematically, as illustrated in the second sentence in Example (2), whose topic is "Wukui," a person. The point at which a topic shift occurs may be taken as a point of meaning completeness, indicated by the use of a period, as Example (2) exemplifies.

[Ex 2:]

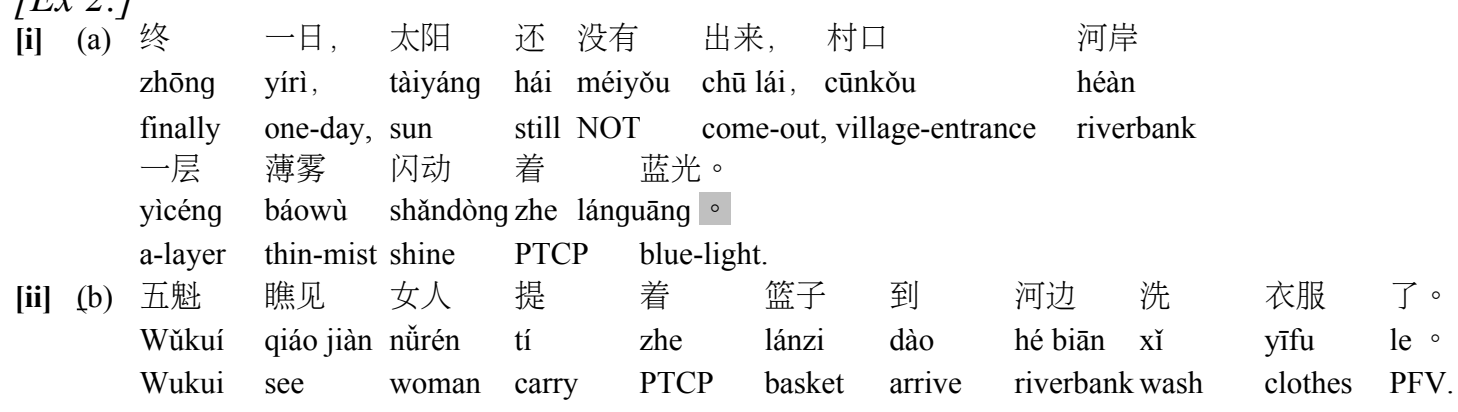

Second, a "character shift" occurs when the character or person of concern shifts from that in one block of clause to a different one in a subsequent block of clause. When the characters are also the topics of the two blocks of clauses, a character shift becomes a subtype of topic shift. In Example (1), the character of concern is "grandpa" in clause (d) and changes to "Cuicui" in next block of clauses (e-k). A character shift may indicate meaning completeness, as the period at the end of clause (d) in Example (1) illustrates.

Third, a "category shift" occurs when the category of activities or behaviors described changes from one block of clauses to another block (e.g., from physical activities to psychological activities), even if these behaviors or activities are performed by the same person. This is illustrated in Example (3), in which clauses (d-f) talk about physical activities of the "Third Master," while clause (f) shifts to describing his psychological activities. Such a category shift may indicate meaning completeness.

[Ex 3:]

[i] (a)

(b)

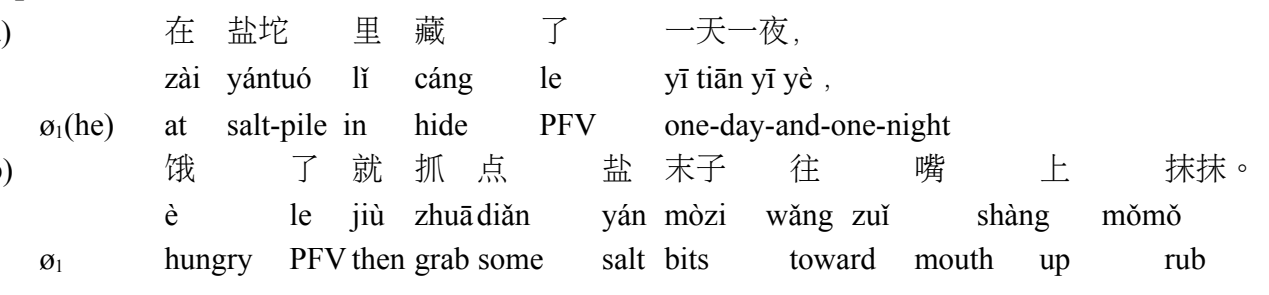




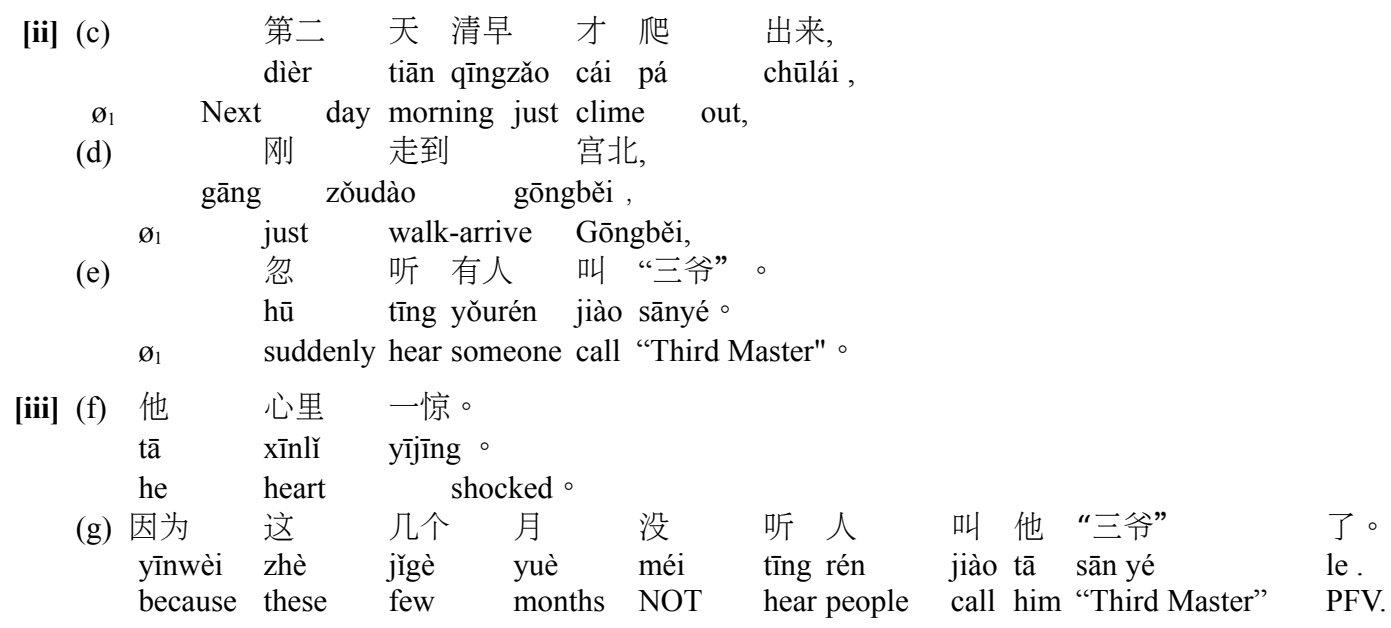

Finally, a "time shift" or "space shift" occurs when there is an obvious change in time or space from one block of clauses to another, even if the topic, character of concern, and category of activities remain the same. For example, a block of clauses may describe the physical activities of a person at one time and/or in one place, while the next block may continue talking about the same person's physical activities at a different time and/or in a different place. A time or space shift, generally marked explicitly by a time or place expression, may indicate completeness. For example, in Example (3), there is a time shift between clauses (a-b) and (c-e), as indicated by "the next morning" at the beginning of clause (c), and the preceding clause is punctuated with a period.

Notably, the factors of character, time, and space have been extensively explored in text processing studies. In particular, the Event Indexing Model (EIM) proposes that people use the general perceptual apparatus to build situation models from narrative texts (Zwaan, Langston, \& Graesser, 1995). In the EIM, events are conceptualized as activated memory nodes, and a story is represented as a set of memory nodes and the connections between them. Each memory node is coded for time, space, characters, objects, and goals (or causes), and a change in these elements activates a new memory node. Our hypothesis that a shift in character, category of activities, time, or space may indicate meaning completeness and therefore prompt the start of a new meaning aligns with the ideas of the EIM.

\section{Methods}

\section{Materials}

We selected 15 short passages from a number of well-known modern Chinese novels and removed all punctuation marks from those passages. The original passages contained commas and periods only. Eight passages were assigned to the training group and the other seven to the 
testing group (see the Participants section below). ${ }^{1}$ The actual passages assigned to the training and testing groups (henceforth stimuli texts) are presented in Appendices A and B and detailed information about the original, modified, and annotated passages is summarized in Table 1.

Table 1 Information about the passages used in the training and testing groups

\begin{tabular}{lcc}
\hline Counts & Training Group & Testing Group \\
\hline Number of participants & 80 & 50 \\
Number of passages & 8 & 7 \\
Number of characters in all passages & 894 & 882 \\
Number of periods in the original passages & 32 & 30 \\
Number of commas in the original passages & 56 & 57 \\
Number of punctuation marks removed & 88 & 87 \\
Number of temporal relations & 6 & 7 \\
Number of contingency relations & 19 & 10 \\
Number of comparison relations & 3 & 7 \\
Number of expansion relations & 32 & 41 \\
Number of elaboration relations & 10 & 6 \\
Number of explicit markers for the five semantic relations & 30 & 26 \\
Number of other/no semantic relations & 20 & 16 \\
Number of topic shifts & 7 & 12 \\
Number of character shifts & 12 & 4 \\
Number of category shifts & 8 & 5 \\
Number of time shifts & 9 & 6 \\
Number of space shifts & 10 & 2 \\
\hline
\end{tabular}

\section{Participants}

Altogether, 130 native Mandarin Chinese speakers (95 female, 35 male) volunteered to participate in the study, and all participants received a small remuneration for their time. Participant age ranged from 21 to 29 years $(\mathrm{M}=24.5, \mathrm{SD}=0.75)$. Among the participants, 56 were undergraduate students majoring in English-Chinese translation, 20 were undergraduate

\footnotetext{
${ }^{1}$ The passages for the training group were selected from fuxi fuxi (by Liu Heng), shenbian (by Feng Jicai), biancheng (by Shen Congwen), shoujie (by Wang Zeqi), qiqiechengqun (by Su Tong), wukui (by Jia Pinwa), and weicheng (by Qian Zhongshu). The passages for the testing group were selected from shoujie (by Wang Zeqi), qinqiang (by Jia Pinwa), weicheng (by Qian Zhongshu), nanrende yiban shi nüren (by Zhang Xianliang), xizao (by Yang Jiang), furongzhen (by Gu Hua), and tapu (by Liu Zhenyun).
} 
students majoring in computer science, 52 were postgraduate students majoring in Chinese linguistics or English-Chinese translation, and two had a $\mathrm{PhD}$ in linguistics. Given their native speaker status and educational background, all participants were highly proficient in reading Chinese and familiar with the use of punctuation marks in written Chinese. The 130 participants were divided into two groups, with 80 in the training group and 50 in the testing group.

\section{The re-punctuation task}

The participants were asked to re-punctuate the stimuli texts assigned to their corresponding group. Specifically, each participant received a sheet of paper containing the stimuli texts with all punctuation marks replaced with blanks and was required to fill in those blanks using commas and periods only with a pen. There was no time requirement for the re-punctuation task, and all participants completed the task in 10 to 20 minutes. The participants also provided information about their age, gender, and educational background at this time. After collecting the sheets from the participants, we recorded their responses and background information in the computer.

\section{Stimuli text annotation}

To test the three hypotheses discussed earlier, we analyzed and annotated each stimuli text in a number of ways, including the length and syntactic status of each clause prior to each blank, the semantic relation between each adjacent pair of clauses (i.e., temporal, contingency, comparison, expansion, elaboration, or other/no relation), the use of any explicit semantic markers indicating one of the five semantic relations of interest, and all instances of the types of semantic shift discussed above (i.e., topic, character, category, time, or space). The annotation was done by two L1 Chinese postgraduate students majoring in Chinese linguistics. The annotators received training from the first author and achieved over $80 \%$ agreement on a pilot passage. They then independently annotated all passages and met to resolve all discrepancies. This annotation work was carried out before the re-punctuation test was taken. The participants in the experiments were not provided with the annotation information. The annotators did not know how the participants filled in punctuation marks.

\section{Statistical and machine-learning methods}

For both the training group and the testing group, the data gathered from the re-punctuation experiment and the annotated stimuli texts were merged ${ }^{2}$. We refer to the merged data for the two groups the Training dataset and the Testing dataset. The former was used to train statistical and machine learning models, and the latter was used to test those models. As the two datasets used different stimuli texts, this would give us a good sense of the reliability of the trained models on new data. Furthermore, we also randomly divided the Training dataset into two smaller parts,

2 All experimental and annotation data can be accessed at https://osf.io/4u8cs/ 
referred to as the smaller training dataset (75\% of the Training dataset) and the smaller testing dataset ( $25 \%$ of the Training dataset), and used them to train and test statistical and machine learning models as well. Given that the smaller training and testing datasets used the same stimuli texts, we could expect the trained model to perform somewhat better in this case, but a comparison of the performance of the models trained and tested in these two configurations would shed useful light on the stability of the models.

Across the Training and Testing datasets and the smaller training and testing datasets, the same 11 independent variables were hypothesized to affect the same response variable. The response variable, named 'Punctuation,' was a binary variable, coded as either "comma" or "period" depending on what a participant provided in each blank in the stimuli texts. Among the 11 independent variables, six were binary variables, namely, topic shift, character shift, category shift, time shift, space shift, and explicit markers, all of which were coded as either "1" (if present) or "0" (if absent). Four were categorical variables, namely, gender (male or female), education (undergraduate, postgraduate, or Ph.D.), syntactic status (subject-predicate, verb phrase, noun phrase, or adjectival phrase), and semantic relation (temporal, contingency, comparison, expansion, or elaboration). The last variable, clause length (i.e., number of characters in the clause) was numeric. The distribution of the semantic shift variables, explicit markers, and different categories of semantic relations in the Training and Testing datasets can be found in Table 1.

Given the binary nature of the response variable and the diversity of the types of independent variables in our dataset, categorical logistic regression modeling appears to be especially appropriate for assessing the effects of the independent variables on the response variable (Palei \& Das, 2009; Sperandei, 2014). As such, we used the "glm" function in R to train and test two logistic regression models using the data partitions described above. Several additional analyses were then performed to verify the effects observed in the logistic regression models and evaluate the performance of their predictions on the testing datasets. First, we confirmed the significant fixed effects observed in the logistic regression models using Bayesian methods (Gelman et al., 2013), implemented with the R package "brms" (Bürkner, 2017). Second, we used the R package "Ime4" (Bates et al., 2014) to train and test two linear mixed-effect models using the same data partitions and compared the performance of these models against that of the logistic regression models. Third, we used receiver operating characteristic (ROC), k-fold cross-validation, and bootstrap cross-validation to test the validity of the statistical models. Finally, we also trained two decision tree-based machine learning models (Song \& Ying, 2015; Hothorn et al., 2006) using the same data partitions and compared their performance with that of the logistic regression models. The road map of the current study is summarized in Fig. 1. 


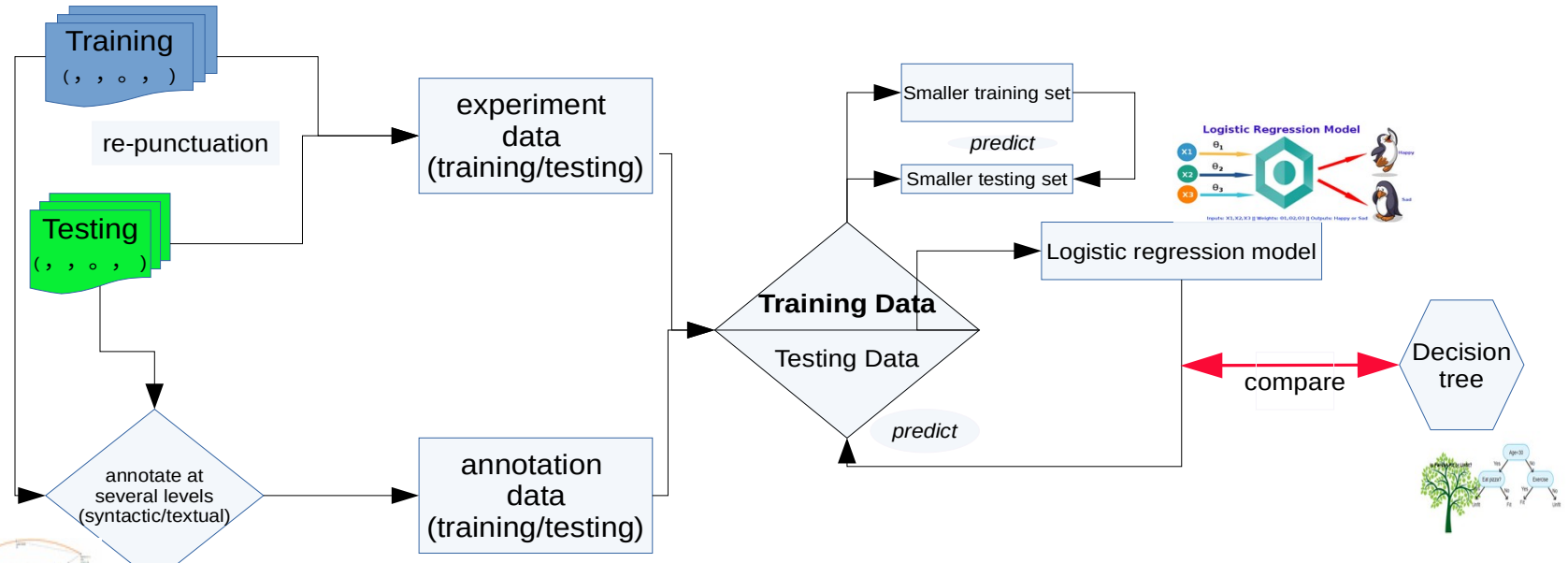

Fig. 1 Road map for the current study

\section{Results}

\section{Significant predictors of native Chinese readers' sentence boundary perception}

To determine whether significant differences in period use existed among the participants, we ran two ANOVAs separately on the Training set and the Testing set using the $\mathrm{R}$ function aov(). The tests revealed significant differences in period use among the 80 participants in the Training set $(\mathrm{F}(2,87)=72.48, p<2 \mathrm{e}-16)$ as well as among the 50 participants in the Testing set $(\mathrm{F}(2,86)=$ $85.55, p<2 \mathrm{e}-16)$. These results confirmed that the native Chinese readers varied substantially in terms of their period use.

We trained a fitting regression model on the smaller training dataset (Model 1) and a second fitting regression model on the entire Training dataset (Model 2) with the same variables discussed above. The following variables: educational level, gender, and syntactic status were not significant predictors in the logistic regression tests. All five types of semantic shifts were significant predictors in both models. Three categories of semantic relations were also found to be significantly predictors in both models, while the contingency and temporal relations were not significant predictors. Explicit semantic relation markers and clause length were also significant predictors in both models. The significant predictors in the models are listed in Table 2 along with their coefficients and the corresponding 95\% confidence intervals.

Table 2 Significant predictors in the logistic regression models

\begin{tabular}{lcc}
\hline Independent variables & Model 1 & Model 2 \\
& (trained on the smaller training dataset) & (trained on the Training dataset)
\end{tabular}




\begin{tabular}{|c|c|c|}
\hline \multirow[t]{2}{*}{ TopicShift } & $1.60 * * *$ & $1.62 * * *$ \\
\hline & {$[1.30,1.89]$} & {$[1.37,1.88]$} \\
\hline \multirow[t]{2}{*}{ CategoryShift } & $1.67 * * *$ & $1.85 * * *$ \\
\hline & {$[1.39,1.94]$} & {$[1.61,2.09]$} \\
\hline \multirow[t]{2}{*}{ CharacterShift } & $1.68 * * *$ & $1.71 * * *$ \\
\hline & {$[1.40,1.97]$} & {$[1.46,1.96]$} \\
\hline \multirow[t]{2}{*}{ TimeShift } & $1.31 * * *$ & $1.25 * * *$ \\
\hline & {$[0.97,1.64]$} & {$[0.96,1.54]$} \\
\hline \multirow[t]{2}{*}{ SpaceShift } & $2.03 * * *$ & $1.99 * * *$ \\
\hline & {$[1.76,2.31]$} & {$[1.76,2.23]$} \\
\hline \multirow[t]{2}{*}{ SemRel(comparison) } & -1.01 & -1.01 \\
\hline & {$[-2.20,0.19]$} & {$[-2.04,0.02]$} \\
\hline \multirow[t]{2}{*}{ SemRel(elaboration) } & $-1.17 * * *$ & $-1.14 * * *$ \\
\hline & {$[-1.46,-0.87]$} & {$[-1.40,-0.88]$} \\
\hline \multirow[t]{2}{*}{ SemRel(expansion) } & $-1.29 * * *$ & $-1.27 * * *$ \\
\hline & {$[-1.52,-1.07]$} & {$[-1.47,-1.08]$} \\
\hline \multirow[t]{2}{*}{ ExplicitMarker } & $-0.34 * *$ & $-0.31 * *$ \\
\hline & {$[-0.60,-0.09]$} & {$[-0.53,-0.09]$} \\
\hline \multirow[t]{2}{*}{ Length } & $0.32 * * *$ & $0.31 * * *$ \\
\hline & {$[0.22,0.42]$} & {$[0.22,0.40]$} \\
\hline $\mathrm{N}$ & 4091 & 5466 \\
\hline AIC & 3273.06 & 4305.16 \\
\hline $\mathrm{BIC}$ & 3348.85 & 4384.44 \\
\hline Pseudo R2 & 0.33 & 0.33 \\
\hline
\end{tabular}

Note. ${ }^{* * *} p<0.001 ; * * p<0.01 ; * p<0.05$.

To better compare the strength and directionality of the significant predictors, we plotted their coefficients in Fig. 2. It is clear that the semantic shift variables have stronger effects than all other significant predictors. While the five semantic shift variables and clause length all had positive effects, explicit markers and the three semantic relation categories all had negative effects. 


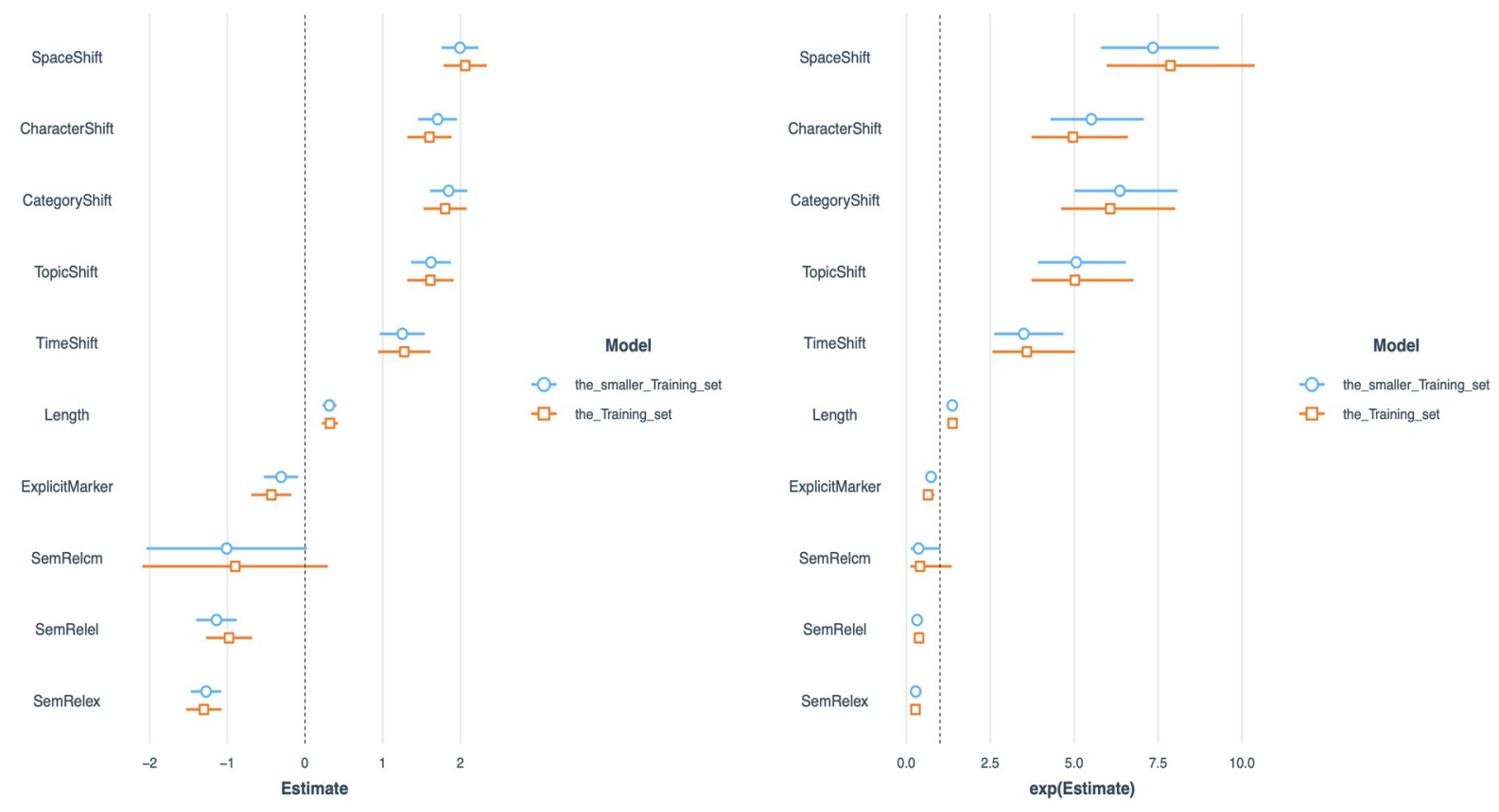

Fig. 2 Coefficient uncertainty as normal distributions. The left panel shows the raw coefficients, and the right panel shows the exponentiation coefficients. SemRelcm = the comparison relation; SemRelel $=$ the elaboration relation; SemRelex $=$ the expansion relation .

We further used Bayesian methods to confirm the significant fixed effects observed in the logistic regression model with the "glm" function in R. The same significant effects were replicated in the best Bayesian fitting model, as indicated by the "rhat" values of 1.0 of the same significant predictors in the "brms" package (Bürkner, 2017). Fig. 3 presents the posterior distribution of the significant predictors in the best Bayesian fitting model. The effects of the significant predictors in this model largely converged with those observed in the logistic regression model. Again, five semantic shift variables and sentence length positively affected native Chinese readers' sentence boundary judgments, while three semantic relation categories and the use of explicit markers negatively affected such judgments. 


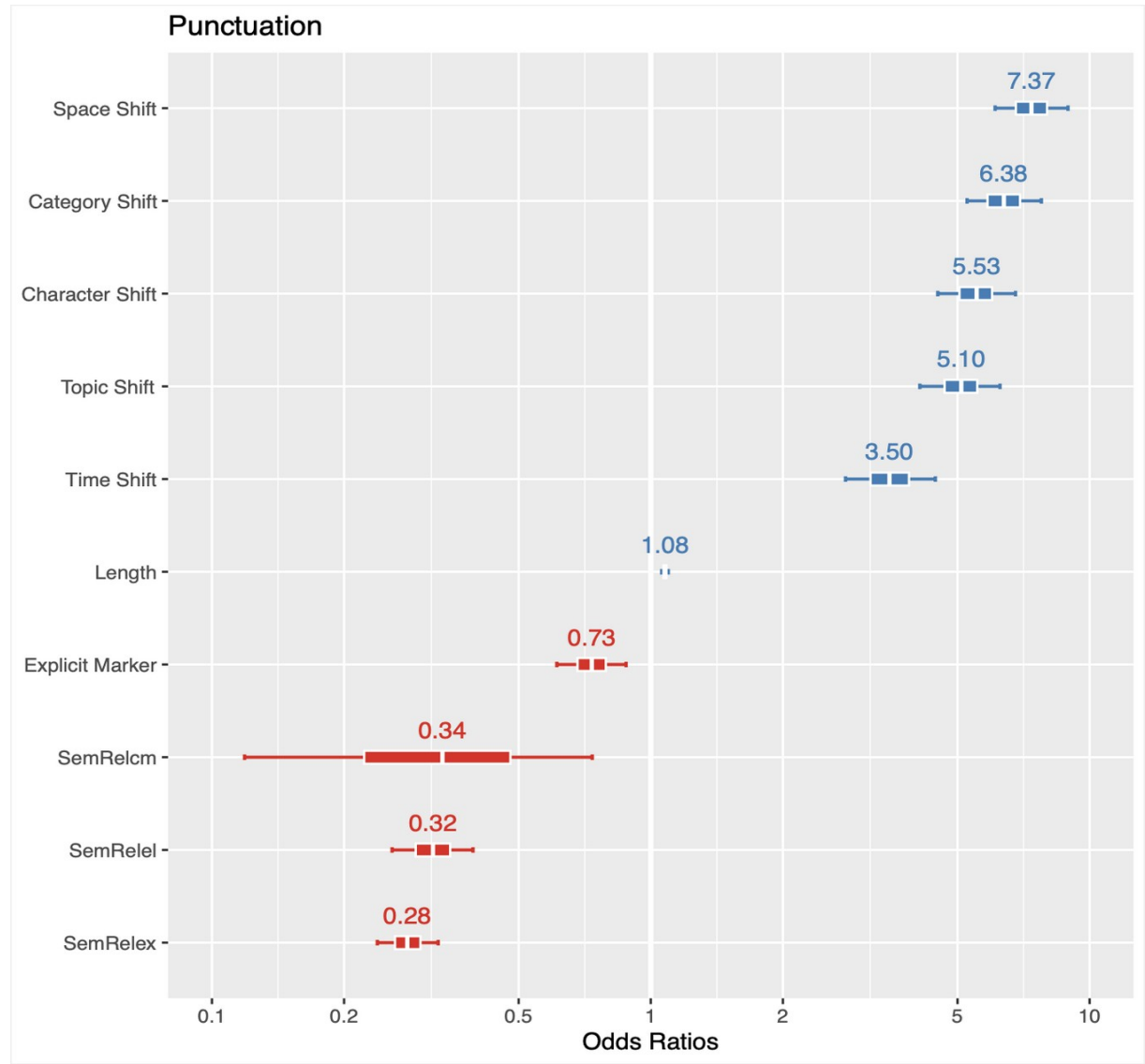

Fig. 3 The posterior distribution of significant predictors in the Bayesian fitting model.

To evaluate the reliability of the two logistic regression models trained, we used Model 1 and Model 2 to predict native Chinese readers' period use on the smaller testing data and the Testing data, respectively. Model 1 correctly predicted $76.36 \%$ of the periods used in the smaller testing dataset, while Model 2 correctly predicted $75.47 \%$ of the periods used in the Testing dataset, indicating good stability of the models trained. The performance of these models was comparable to the performance of linear mixed effect models (implemented with the "Ime4" function in R) trained and tested on the same datasets, which predicted $77.01 \%$ of the periods used in the smaller testing dataset and $75.01 \%$ of the periods used in the Testing dataset. The $\mathrm{R}$ scripts for training and testing the logistic regression models and linear mixed-effect models can be found in Appendix C. The validity of the logistic regression model was further confirmed through ROC, k-fold cross-validation, and bootstrap cross-validation, as detailed in Appendix D.

\section{Results of a decision tree-based machine learning model}

The results of the logistic regression model (Model 2) were also compared against those of a decision tree-based machine learning model that considered the same variables. Binary 
classification with the decision tree-based model was executed using an $\mathrm{R}$ package (party) (Hothorn et al., 2006) (see Appendix $\mathrm{C}$ for the R scripts). The decision tree model trained on the smaller training dataset achieved $84.75 \%$ precision on the smaller testing dataset, higher than the $76.36 \%$ achieved by the logistic regression model. The decision tree model trained on the Training dataset (shown in Fig. 4) achieved $81.63 \%$ precision on the Testing dataset, also higher than the $75.47 \%$ achieved by the logistic regression model. While the logistic regression model achieved somewhat lower precision than the decision tree-based machine learning model, it is nevertheless more cognitively interpretable than the latter. Meanwhile, the results of the decision tree-based machine learning model further attested to the effectiveness of the variables considered in the current study for predicting native Chinese readers' sentence boundary perception.

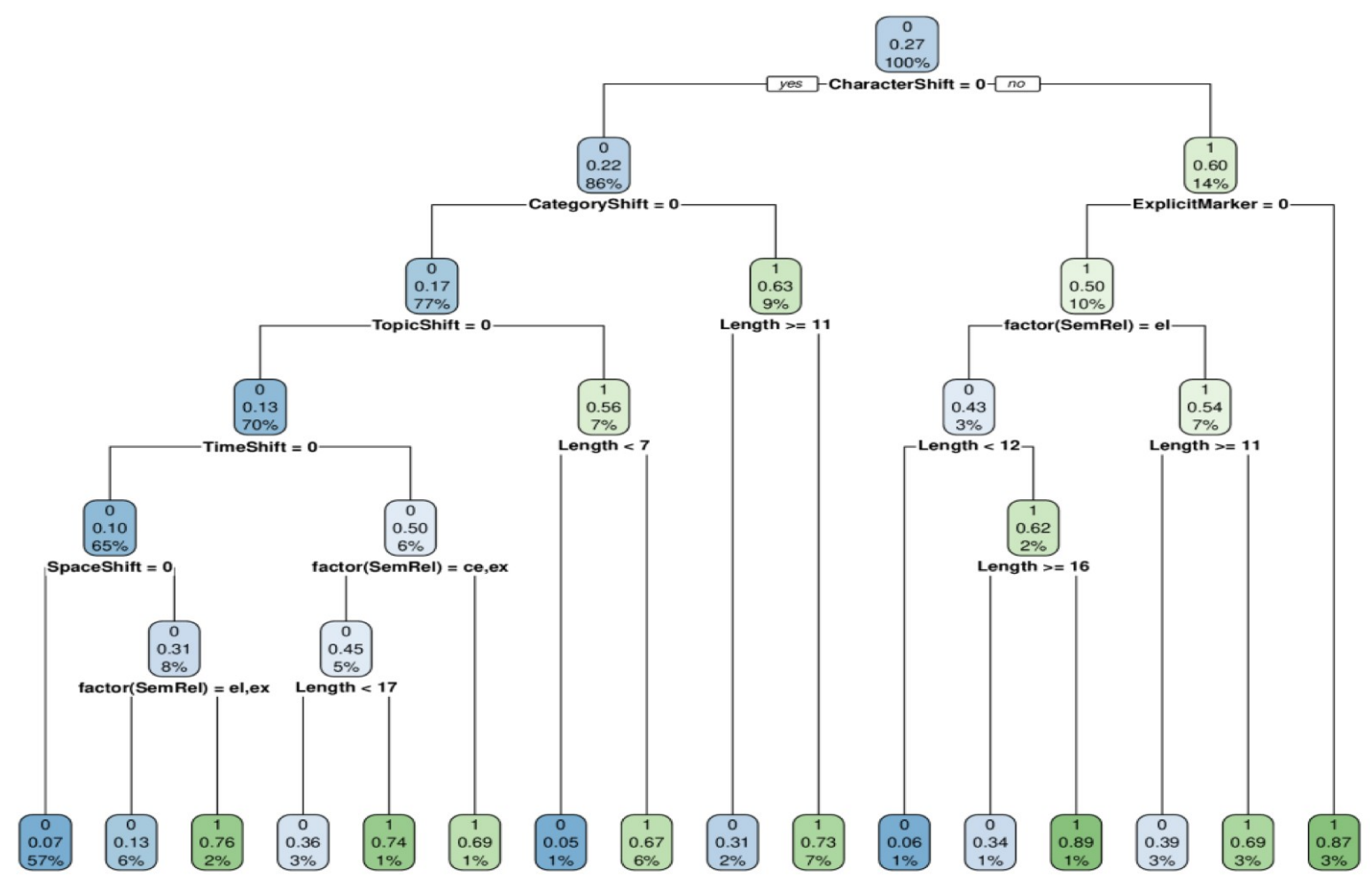

Fig. 4 A decision tree-based machine learning model for sentence boundary detection

\section{Discussion}

The logistic regression analysis yielded a number of factors that significantly affected native Chinese readers' sentence boundary perception. Several predictors negatively affected the participants' sentence boundary judgments, indicating native Chinese readers were more likely to use a comma instead of a period in a blank when these predictors were present. Specifically, 
when an explicit marker of semantic relation was present or when the semantic relation between two clauses was that of comparison, expansion, or elaboration, the participants were more likely to use a comma than a period between those two clauses. These results appear to align with the positive effects observed for semantic shifts in topic, character, category, time, and space. In other words, when a clause appears to be a semantic continuation of the previous clause, particularly when that continuation is marked by an explicit semantic marker, native Chinese readers are more likely to see the two clauses as parts of the same complete meaning and thus less likely to insert a period as a sentence boundary marker between them. On the other hand, when a clause exhibits a clear semantic shift from the previous clause, native Chinese readers are more likely to see the current clause as initiating a new meaning or idea and thus more likely to insert a period at the end of the preceding clause to indicate the completeness of a meaning at that point. It can be seen that explicit markers, semantic relations, and semantic shifts function not at the level of syntactic structures but at the level of meaning and discourse flow (e.g., Moder \& Martinovic-Zic, 2004). In addition, native Chinese readers were also more likely to use periods after longer clauses than after shorter ones. This may not be surprising, as on average longer clauses provide more room for meaning expression and also impose higher cognitive loads to language users than shorter clauses (Mikk, 2008). In terms of the magnitude of the effects observed for the significant predictors, the semantic shift variables exhibited the largest effect, followed by the three semantic relation categories, while explicit markers and clause length demonstrated smaller effects. These differences shed light on the greater importance of semantic shifts and relations than explicit markers and clause length in native Chinese readers' sentence boundary perception.

Gender, educational level, and the "syntactic status" of the clause (i.e., subject-predicate, verb phrase, noun phrase, or adjectival phrase) did not significantly affect the participants' sentence boundary perception. The insignificant effect of "syntactic status" is particularly worth noting. As mentioned earlier, in many other languages such as English sentence boundaries in written texts tend to be constrained by well-established syntactic rules. That is, a complete sentence is generally expected to have a complete sentential structure, with some stylistic and/or contextual exceptions. Our results indicate that native Chinese readers' sentence boundary perception in written Chinese texts is affected primarily by semantic factors pertaining to meaning completeness at the discourse level rather than syntactic factors pertaining to structural completeness. In this sense, the concept of sentencehood in Chinese as tacitly understood by native Chinese speakers appears to be different from that defined syntactically in other languages.

The model trained and tested on data from the same stimuli texts and one trained and tested on data from different stimuli texts demonstrated comparably satisfactory performance $(76.36 \%$ vs. $75.47 \%$ ) in predicting the participants' period use. The effects observed for the significant 
predictors in the logistic regression model were also confirmed using Bayesian methods and validated using ROC, k-fold cross-validation, and bootstrap cross-validation. A decision treebased machine learning model, which achieved somewhat better performance in predicting the participants sentence boundary perception than the logistic regression model, further confirmed the usefulness of the independent variables considered in the current study. Overall, these results suggest that the logistic regression was stable and reliable may serve as an efficient and generalizable model for sentence boundary detection in written Chinese texts. It can also be treated as a simple cognitive model for understanding how native Chinese speakers judge meaning completeness and determine sentence boundaries. Meanwhile, the model's 24.53\% error rate on the Testing dataset may be explained by the subjectivity in meaning completeness judgment discussed in the Introduction and evidenced in the significant differences among the participants revealed by the ANOVA results. It could also be the case that additional factors beyond those explored in the current study may be at play.

A theoretical implication of our findings is that sentences in written Chinese texts may resemble "text-like sentences" often found in spoken or digital English (e.g., Lotherington \& Xu, 2004), characterized not by complete sentential structures but by blocks of clauses judged to contain a complete meaning. This is the case as native Chinese speakers primarily draw on semantic and discourse information rather than syntactic structural information to determine meaning completeness and sentence boundaries in a block of clauses. Theoretical explanations of the significant positive effects observed for semantic shifts on native Chinese readers' sentence boundary perception are possible from the lens of the Event Indexing Model (EIM; Zwaan et al., 1995). As mentioned earlier, this model conceptualizes events as activated memory nodes, each coded for time, space, characters, objects, and goals (or causes); a change in these elements activates a new memory node, and the memory nodes and their connections form the representation of the story in a narrative text. Several semantic shifts (i.e., time, space, and character shifts) defined in the current study overlap with the elements in the EIM, and it may be the case that the activation of a new memory node is associated with the initiation of a new meaning or idea in Chinese. Finally, the significant negative effects observed for semantic relations concur with findings from previous efforts in annotating semantic relations between clauses in discourse corpora in Chinese that such relations often reside within sentence boundaries (Webber et al., 2019; Zhou \& Xue, 2015).

\section{Conclusion}

Using data from a re-punctuation experiment and annotated stimuli texts, this study examined the effects of a set of syntactic and semantic factors on native Chinese readers' sentence boundary perception. Our findings revealed significant positive effects of five types of semantic shifts and 
clause length on native Chinese readers' sentence boundary perception and significant negative effects of explicit markers and several categories of semantic relations on such perception. No significant effects were observed for the syntactic status of the clauses or the two basic sociolinguistic factors of gender and educational level. These results showed that native Chinese readers relied primarily on semantic factors relevant to meaning completeness instead of syntactic factors pertaining to structural completeness in judging sentence boundaries in written Chinese texts. The findings also suggest that sentences in written Chinese texts may to a large extent resemble "text-like sentences" in spoken or digital English, characterized not by complete sentential structures but by blocks of clauses judged to contain a complete meaning. Building upon the initial findings of the current study, future research can fruitfully employ additional experimental methods to investigate the effects of additional factors and their interactions (e.g., working memory) to better understand the mechanisms underlying native Chinese speakers' meaning completeness judgment and sentence boundary perception, including in particular the subjectivity and individual variation that exists in such judgment and perception. Future research can also investigate differences in the mechanisms underlying native Chinese speakers' sentence boundary perception in spoken and written Chinese as well as differences in the mechanism underlying Chinese-English bilingual speakers' sentence boundary perception in spoken and/or written Chinese and English.

\section{References}

Alexander, L. G. (2019). Longman English grammar practice. Boston, MA: Addison-Wesley.

Baron, N.S. (2001). Comma and canaries: The role of punctuation in speech and writing. Language Sciences, 23(1), 15-67. https://doi.org/10.1016/S0388-0001(00)00027-9

Bates, D., Mächler, M., Bolker, B., \& Walker, S. (2014). Fitting linear mixed-effects models using lme4. Journal of Statistical Software, 67(1), 1-48. https://doi.org/10.18637/jss.v067.i01

Bürkner, P. C. (2017). BRMS: An R package for Bayesian multilevel models using Stan. Journal of Statistical Software, 80(1), 1-28. https://doi.org/10.18637/jss.v080.i01

Chappell, H., Ming, L., \& Peyraube, A. (2007). Chinese linguistics and typology: The state of the art. Linguistic Typology, 11(1), 187-211. https://doi.org/10.1515/LINGTY.2007.014

Christensen, H., Gotoh, Y., \& Renals, S. (2001). Punctuation annotation using statistical prosody models. In Proceedings of the ISCA Tutorial and Research Workshop on Prosody in Speech Recognition and Understanding (pp. 35-40). Red Bank, NJ: International Speech Communication Association. 
De Leeuw, J. (2006). Principal component analysis of binary data by iterated singular value decomposition. Computational Statistics and Data Analysis, 50(1), 21-39. https://doi.org/10.1016/j.csda.2004.07.010

Gelman, A., Carlin, J. B., Stern, H. S., Dunson, D. B., Vehtari, A., \& Rubin, D. B. (2013). Bayesian data analysis. Boca Raton, FL: CRC Press.

Heggie, L., \& Wade-Woolley, L. (2018). Prosodic awareness and punctuation ability in adult $\begin{array}{llll}\text { readers. } & \text { Reading } & \text { Psychology, } & \text { 39(2), }\end{array}$ https://doi.org/10.1080/02702711.2017.1413021

Hirotani, M., Frazier, L., \& Rayner, K. (2006). Punctuation and intonation effects on clause and sentence wrap-up: Evidence from eye movements. Journal of Memory and Language, 54(3), 425-443. https://doi.org/10.1016/j.jml.2005.12.001

Hothorn, T., Hornik, K., \& Zeileis, A. (2006). Party: A laboratory for recursive part (y) itioning. $R$ package version 0.9-11.

Huang, B., \& Liao, X. (2007). Xiandai Hanyu [Modern Chinese] (4th Edition). Beijing: Higher Education Press.

Huang, J., \& Shi, D. (2016). A reference grammar of Chinese. Cambridge: Cambridge University Press.

Huddleston, R., \& Pullum, K. G. (2002). The Cambridge grammar of the English language. Cambridge: Cambridge University Press.

Li, C. N., \& Thompson, S. A. (1989). Mandarin Chinese: A functional reference grammar. Berkeley: University of California Press.

Li, X., Rayner, K., \& Cave, K. R. (2009). On the segmentation of Chinese words during $\begin{array}{llll}\text { reading. } & \text { Cognitive } & \text { Psychology, } & \text { 58(4), }\end{array}$ https://doi.org/10.1016/j.cogpsych.2009.02.003

Lu, J. M. (2013). A Course in Modern Chinese Grammar (Forth Edition). Beijing: Peking University Press.

Kassambara, A., \& Mundt, F. (2016). Factoextra: Extract and visualize the results of multivariate data analyses. $R$ package version 1.0.6.

Kulig, A., Kwapień, J., Stanisz, T., \& Drożdż, S. (2017). In narrative texts punctuation marks obey the same statistics as words. Information Sciences, 375, 98-113. https://doi.org/10.1016/j.ins.2016.09.051

Li, W. (2004). Topic chains in Chinese discourse. Discourse Processes, 37(1), 25-45. https://doi.org/10.1207/s15326950dp3701_2 
Lai, W., Yuan, J., Li, Y., Xu, X., \& Liberman, M. (2016). The rhythmic constraint on prosodic boundaries in Mandarin Chinese based on corpora of silent reading and speech perception. In INTERSPEECH 2016 (pp. 87-91). San Francisco: ISCA.

Liu, B., Wang, Z., \& Jin, Z. (2010). The effects of punctuations in Chinese sentence comprehension: An ERP study. Journal of Neurolinguistics, 23(1), 66-80. https://doi.org/10.1016/j.jneuroling.2009.08.004

Liu, Y., Shriberg, E., Stolcke, A., Hillard, D., Ostendorf, M., \& Harper, M. (2006). Enriching speech recognition with automatic detection of sentence boundaries and disfluencies. IEEE Transactions on Audio, Speech, and Language Processing, 14(5), 1526-1540. https://doi.org/10.1109/TASL.2006.878255

Lotherington, H., \& Xu, Y. (2004). How to chat in English and Chinese: Emerging digital $\begin{array}{llll}\text { language } & \text { convention. } & \text { ReCALL, } & \text { 308-329. }\end{array}$ https://doi.org/10.1017/S0958344004000527

Lu, S., \& Zhu, D. (2013). Yufa xiuci jianghua [Lectures on grammar and rhetoric]. Beijing: Commercial Press.

Ma, G., Li, X., \& Rayner, K. (2014). Word segmentation of overlapping ambiguous strings during Chinese reading. Journal of Experimental Psychology: Human Perception and Performance, 40(3), 1046. https://doi.org/10.1037/a0035389

Mikk, J. (2008). Sentence length for revealing the cognitive load reversal effect in text $\begin{array}{llll}\text { comprehension. } & \text { Educational } & \text { Studies, } & 34(2),\end{array}$ https://doi.org/10.1080/03055690701811164

Marslen-Wilson, W. D. (1975). Sentence perception as an interactive parallel process. Science, 189(4198), 226-228. https://doi.org/10.1126/science.189.4198.226

Moder, C. L., \& Martinovic-Zic, A. (Eds.). (2004). Discourse across languages and cultures. Amsterdam: John Benjamins.

Niikuni, K., \& Muramoto, T. (2014). Effects of punctuation on the processing of temporarily ambiguous sentences in Japanese. Japanese Psychological Research, 56(3), 275-287. https://doi.org/10.1111/jpr.12052

Nunberg, G. (1990). The linguistics of punctuation. Stanford, CA: Center for the Study of Language.

Palei, S. K., \& Das, S. K. (2009). Logistic regression model for prediction of roof fall risks in bord and pillar workings in coal mines: An approach. Safety Science, 47(1), 88-96. https://doi.org/10.1016/j.ssci.2008.01.002

Partridege, E. (1998). You have a point there: A guide to punctuation and its allies. London: Routledge. 
Paul, W. (2008). The serial verb construction in Chinese: A tenacious myth and a Gordian knot. The Linguistic Review, 25(3-4), 367-411. https://doi.org/10.1515/TLIR.2008.011

Pynte, J., \& Kennedy, A. (2007). The influence of punctuation and word class on distributed processing in normal reading. Vision Research, 47(9), 1215-1227. https://doi.org/10.1016/j.visres.2006.12.006

Scholes, R. J., \& Willis, B. J. (1990). Prosodic and syntactic functions of punctuation: A contribution to the study of orality and literacy. Interchange, 21(3), 13-20. https://doi.org/10.1007/BF01809416

Shi, D. (2000). Topic and topic-comment constructions in Mandarin Chinese. Language, 76(2), 383-408. https://doi.org/10.2307/417661

Sperandei, S. (2014). Understanding logistic regression analysis. Biochemia Medica, 24(1), 1218. https://doi.org/10.11613/BM.2014.003

Song, Y. Y., \& Ying, L. U. (2015). Decision tree methods: applications for classification and prediction. Shanghai Archives of Psychiatry, 130. https://doi.org/10.11919/j.issn.1002-0829.215044

Sun, K., \& Wang, R. (2019). Frequency distributions of punctuation marks in English: Evidence from large-scale corpora. English Today, 23-35. https://doi.org/10.1017/S0266078418000512

Sun, K. (2018). Approaching the double-nominal construction in Mandarin Chinese through the semantic-cognitive interaction. Studia Linguistica, 72(3), 687-724. https://doi.org/10.1111/stul.12085

Sun, K. (2019). Integration functions of topic chains in Chinese discourse. Acta Linguistica Asiatica, 9(1), 29-57. http://doi.org/10.4312/ala.9.1.29-57

Schou, K. (2007). The syntactic status of English punctuation. English Studies, 88(2), 195-216.

Steinhauer, K., \& Friederici, A. D. (2001). Prosodic boundaries, comma rules, and brain responses: The closure positive shift in ERPs as a universal marker for prosodic phrasing in listeners and readers. Journal of Psycholinguistic Research, 30(3), 267-295. https://doi.org/10.1023/A:1010443001646

Webber, B., Prasad, R., Lee, A., \& Joshi, A. (2019). The Penn Discourse Treebank 3.0 annotation manual. Philadelphia: University of Pennsylvania.

Xue, N., \& Yang, Y. (2011). Chinese sentence segmentation as comma classification. In Proceedings of the 49th Annual Meeting of the Association for Computational Linguistics: Human Language Technologies (pp. 631-635). Portland, OR: Association for Computational Linguistics. 
Yen, M. H., Radach, R., Tzeng, O. J. L., \& Tsai, J. L. (2012). Usage of statistical cues for word boundary in reading Chinese sentences. Reading and writing, 25(5), 1007-1029. https://doi.org/10.1080/17470218.2015.1061030

Wu, F., \& He, Y. (2015). Some typological characteristics of Mandarin Chinese syntax. In Wang, W. S., \& Sun, C. (eds). The Oxford handbook of Chinese linguistics (pp. 379-392). Oxford: Oxford University Press.

Zhou, Y., \& Xue, N. (2015). The Chinese Discourse TreeBank: A Chinese corpus annotated with discourse relations. Language Resources and Evaluation, 49(2), 397-431. https://doi.org/10.1007/s10579-014-9290-3

Zwaan, R. A., Langston, M. C., \& Graesser, A. C. (1995). The construction of situation models in narrative comprehension: An event-indexing model. Psychological Science, 6(5), 292297. https://doi.org/10.1111/j.1467-9280.1995.tb00513.x 


\section{Appendices}

\section{A. The stimuli in the training set}

A. 秋天 1 王菊豆蒙着花手巾风摆杨柳似的出了村庄 2 逢人便说去乡里赶集 3 却悄悄地赴了十几里之外的双清庵 4 焚了八 炷香 5 给一个泥胎磕了无数的头 6 暗暗地跟了一个老尼姑走到大殿的后山墙 7 噗通一声就趾了下来 8 尼姑问明道理 9 幽 幽一乐 10 说她刚才拜错了偶像。

B. 他不信 1 以为飞来凤不理他 2 便隔着那堵磨砖对缝的高墙 3 往里边扔砖头 4 把院子里的金鱼缸砸碎 5 (这)引出展家几 个男仆要抓他 6 (男仆抓他) 吓得他一口气跑到海河边 7 在盐坨里藏了一天一夜 8 饿了就抓点盐末子往嘴上抹抹 9 第二天 清早才爬出来 10 刚走到宫北 11 忽听有人叫"三爷"12 他心里一惊 13 因为这几个月没听人叫他"三爷"了 14 扭头燋 15 原来是广来洋货店的掌柜杨殿起。

C. 船夫方面还以为上次歌声既归二老唱的 1 在此后几个日子里 2 自然还会听到那种歌声 3 一到了晚间就故意从别样事情上 4 促翠翠注意夜晚的歌声 5 两人吃完饭坐在屋里 6 因屋前滨水 7 长脚蚊子一到黄昏就嗡嗡的叫着 8 翠翠便把蒿艾束成的 烟包点燃 9 向屋中角隅各处晃着驱逐蚊子 10 晃了一阵 11 估计全屋子里已为蒿艾烟气重透了 12 才搁到床前地上去 13 再坐在小板登上来听祖父说话。

D. 到了一个河边 1 有一只船在等着他们 2 船上有一个五十来岁的瘦长瘦长的大伯 3 船头蹲着一个跟明子差不多大的女孩子 4 在剥一个莲蓬吃 5 明子和舅舅坐到舱里 6 船就开了 7 明子听见有人跟他说话 8 是那个女孩子。

E. 黄昏的时候 1 有一群人围坐在花园里听飞浦吹萧 2 飞浦换上丝绸衫裤 3 更显出他的惆傥风流 4 飞浦持萧坐在中间 5 四面 听萧的多是飞浦做生意的朋友 6 这时候这群人成为陈府上下观注的中心 7 仆人们站在门廊上远远地观察他们 8 窃窃私语。 F. 女人的眉宇间骤然泛红了 1 意识到自己并不是五魁的老婆 2 五魁只是救自己的一个贫贱羊倌一个光棍 3 在这荒天野地的世 界里 4 五魁能自觉地将睡窝一分为二 5 女人为坦白蓛诚的五魁而感动了 6红日坠山 7 乌鸦飞来 8 天很快就黑了9 五魁安置 了女人睡好 10 燃起了松油节 11 便坐于旁边说许多豪迈的话 12 叮嘱夜里放心安睡。

G. 吃完点心 1 大家上车 2 茶房把伞交还孙小姐 3 湿漉漉加了热气腾滕 4 这时候已经下午两点钟 5 一行人催洋车夫赶路 6 走不上半点钟 7 有一个很陡的石子坡 8 拉李先生那只大铁箱的车夫 9 载重路滑 10 下坡收脚不住 11 摔了一交 12 车子翻了。 H. 罗汉大爷 1 心头火起 2 一歪一斜地转着 3 想寻找一件利器 4 在开挖引水渠的工地上 5 他找到一柄锋利的铁锹 6 他毫 无拘禁地走 7 叫骂 8 忘了百步之外的人与狗 9 他自由自在 10 不自由都是因为怕。

\section{B. The stimuli in the testing set}

A. 这里的习惯 1 牛卸了轭 2 饮了水 3 就牵到一口和好泥水的“汪"里 4 由它自己打滚扑腾 5 弄得全身都是泥浆 6 这样蚊 子就咬不通了 7 低田上水 8 只要一挂十四轧的水车 9 两个人车半天就够了 10 明子和小英子就伏在车杠上 11 不紧不慢地 踩着车轴上的拐子 12 轻轻地唱着明海向三师父学来的各处山歌 13 打场的时候 14 明子能替赵大伯一会 15 让他回家吃 饭。 
B. 院庭里很静 1 正午的阳光从玉兰树浓密的枝叶间隙投射到砖地上2两只盛满水的木桶挌在井台上 3 洗衣盆扣在墙根下 4 显得很凌乱 5 黑娃把木盆拎起来放到井台下的渗坑边上 6 那是小女人往常洗衣服的地方 7 看看庭院里没有任何异常的变化 8 他撩起布衫下襟擦擦脸上的汗 9 就走出了这个空寂安溢的院子 10 他一走进牛棚马号顺手掩插了门板 11 扑通一声仰躺在 大炕上 12 紧张的肌肉一下子松弛下来 13 心似乎这会儿才稳定在原来的位置上。

C. 明天一清早 1 船没进港就老远停了 2 磨到近中午 3 船公司派两条汽油船来 4 摆渡客人上岸 5 头二等跟一部分三等乘客 先上第一条船 6 这船的甲板比大轮船三等舱的甲板低五六尺 7 乘客得跳下去 8 水一荡漾 9 两船间就距离着尺把的海 10 张了口等人掉进去 11 乘客同声骂船公司混帐 12 可是人人都奋不顾身地跳了 13 居然没出岔子。

D. 果然, 她从梁上飘落下来了 1 先是一团不成形的彩色的雾气 2 落到地面上 3 便立刻凝聚成了一个活生生的美丽的姑娘 4 和老劳改犯说的一样 5 两条大辫子油光水滑的 6 长长的睫毛 7 水灵灵的眼睛 8 皮肤即使在昏黄的油灯下也显出白中透红的光 彩 9 她还穿着冬天的红棉袄 10 脚上果真穿的是红鞋 11 简徆的小土坏房因为她的到来而变得喜气洋洋了。

E. 姚宓未及出门 1 姜敏就来了 2 她穿一条灰色西装裤 3 上衣是墨绿对襟棉袄 4 胸口露出鲜红的毛衣 5 小鸟依人般飞了进来 6 姜敏身材娇小 7 白嫩的圆脸 8 两眼水汪汪地亮 9 她惯爱垂下长长的睫毛 10 斜着眼向人一瞄 11 大有钩魂摄魄的伎俩 12 她两眼的磁力 13 把她的小鼻子和参差不齐的牙齿都掩盖了。

F. 谷燕山一直在留心倾听公路上有无汽车开过的声音 1 胡玉音睡下后 2 他索性转出铺门 3 顶风冒雪来到公路上守候 4 哪怕 是横睡在路上 5 他都要把随便哪一辆夜行的车子截住 6 过了一会儿 7 雪停了 8 风息了9 9 满世界的白雪 10 把夜色映照得明晃 晃的。

G. 青青的野地里 1 一片发白 2 附近的村子里 3 鸡叫声此起彼伏 4 我忽然感至有些冷 5 看到身边的李爱莲 6 也在打颤 7 我 忙把外衣脱下 8 披到她身上 9 她看着我 10 也没推辞 11 只是深情地看看我 12 慢慢将身子贴到我的怀里。

\section{R scripts}

\section{C.1. Logistic regression model}

C.1.1. The model

mod $=$ glm $($ formula $=$ Punctuation $\sim$ TopicChange + CategoryChange + CharacterChange + TimeChange + SpaceChange + SemRel + ExplicitMarker + Length, family $=$ binomial (), data $=$ train $)$ \#establish smaller testing data, "test1".

smp_size <- floor $(0.75$ * nrow(train)

set.seed(123)

train_ind <-sample(seq_len(nrow(train)), size = smp_size $)$

train $1<-$ train[train_ind, ]

test $1<-$ train[-train_ind, ]

cats. prob = predict $(\bmod$, test 1, type="response")

cats. pred = rep("comma", dim(test1)[1])

cats. pred[cats. prob >.5] = "period"

table(cats.pred, test 1 \$pun.f)

\#cats.pred comma period 


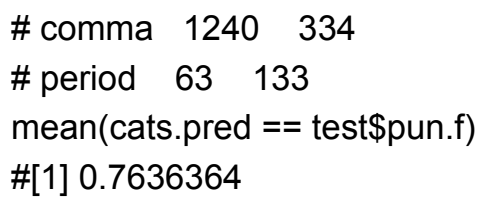

C.1.2 Predictions on the Testing dataset

\#"test" is the real test data

cats.pred $=\operatorname{rep}(" c o m m a ", \operatorname{dim}($ test)[1])

cats.pred[cats.prob >.5] = "period"

table(cats.pred, test\$pun.f)

cats.pred comma period

\# comma 1894626

\# period $40 \quad 50$

mean(cats.pred $==$ test\$pun.f)

\#[1] 0.7554023

C.1.3. Decision tree and its predictions on the Testing dataset

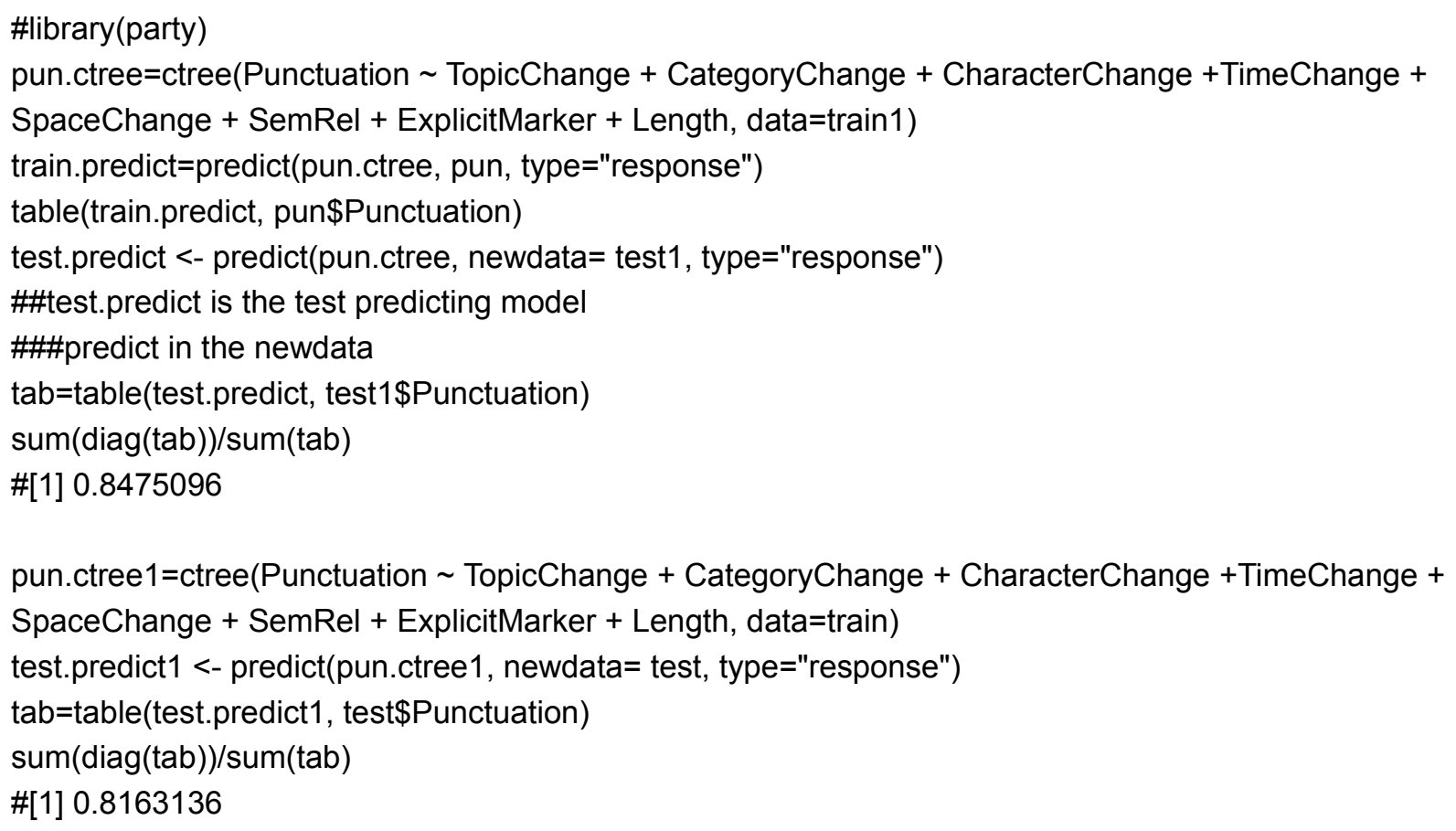

\section{C.2. Mixed-effect models}

\section{C.2.1. Model comparisons}

\#\#We choose the best mixed-effect model anova $(\operatorname{Im} 1, \operatorname{Im} 0)$

\#refitting model(s) with ML (instead of REML) 
\#Models:

\#lm1: Punctuation $\sim$ TopicShift + CategoryShift + CharacterShift + TimeShift + SpaceShift + SemRel + ExplicitMarker + Length $+(1 \mid$ Gender $)$

\#Im0: Punctuation TopicShift + CategoryShift + CharacterShift + TimeShift + SpaceShift + SemRel + ExplicitMarker + Length $+(1 \mid$ Education $)$

\# npar AIC BIC logLik deviance Chisq Df $\operatorname{Pr}(>$ Chisq)

\#Im1 $144187.54280-2079.7 \quad 4159.5$

\#Im0 $144197.54290-2084.8 \quad 4169.5 \quad 0 \quad 0$

anova $(\operatorname{Im} 1, \operatorname{Im} 2)$

\#refitting model(s) with ML (instead of REML)

\#Models:

\#lm1: Punctuation $~$ TopicShift + CategoryShift + CharacterShift + TimeShift + SpaceShift + SemRel + ExplicitMarker + Length $+(1 \mid$ Gender $)$

\#lm2: Punctuation $\sim$ TopicShift + CategoryShift + CharacterShift + TimeShift + SpaceShift + SemRel + ExplicitMarker + Length $+(1 \mid$ Gender $)+(1 \mid$ Education $)$

\# npar AIC BIC logLik deviance Chisq Df $\operatorname{Pr}(>$ Chisq)

\#Im1 $144187.54280 .0-2079.7 \quad 4159.5$

\#Im2 $154187.84286 .9-2078.9 \quad 4157.81 .6963 \quad 1 \quad 0.1928$

anova $(\operatorname{Im} 1, \operatorname{Im} 3)$

\#refitting model(s) with ML (instead of REML)

\#Models:

\#lm1: Punctuation $\sim$ TopicShift + CategoryShift + CharacterShift + TimeShift + SpaceShift + SemRel + ExplicitMarker + Length $+(1 \mid$ Gender $)$

\#Im3: Punctuation TopicShift + CategoryShift + CharacterShift + TimeShift + SpaceShift + SemRel + ExplicitMarker + Length $+(1 \mid$ Gender $)+(1 \mid$ Education $)+$ TimeShift * ExplicitMarker + SpaceShift *

ExplicitMarker

\# npar AIC BIC logLik deviance Chisq Df $\operatorname{Pr}(>$ Chisq)

\#Im1 $144187.54280 .0-2079.7 \quad 4159.5$

\#Im3 $164182.84288 .5-2075.4 \quad 4150.88 .702620 .01289$ *

\#Signif. codes: 0 ‘*** 0.001 ‘**’ 0.01 ‘*’ 0.05 '? 0.1 ' '1

anova( $\operatorname{Im} 3, \operatorname{Im} 2)$

\#Models:

\#Im2: Punctuation TopicShift + CategoryShift + CharacterShift + TimeShift + SpaceShift + SemRel + ExplicitMarker + Length $+(1 \mid$ Gender $)+(1 \mid$ Education $)$

\#Im3: Punctuation $\sim$ TopicShift + CategoryShift + CharacterShift + TimeShift + SpaceShift + SemRel + ExplicitMarker + Length $+(1 \mid$ Gender $)+(1 \mid$ Education $)+$ TimeShift * ExplicitMarker + SpaceShift *

ExplicitMarker

\# npar AIC BIC logLik deviance Chisq Df $\operatorname{Pr}(>$ Chisq)

\#lm2 $144296.44388 .9-2134.24268 .4$

\#Im3 15 4273.2 4372.3 -2121.6 4243.2 25.161 1 5.275e-07 ***

\#Signif. codes: 0 “***' 0.001 '**’ 0.01 ‘*’ 0.05 '? 0.1 “' 1 
\#We use the best model, Im3, to make predictions.

cats. $\operatorname{prob}=\operatorname{predict}(\operatorname{Im} 3$, test 1, type $=$ "response" $)$

cats. prob $=$ predict $(\operatorname{Im} 3$, test 1, type $="$ response")

cats. pred $=\operatorname{rep}(" c o m m a ", \operatorname{dim}($ test1)[1])

cats.pred[cats.prob >.5] = "period"

table(cats.pred, test1\$pun.f)

\#cats.pred comma period

comma 1250373

period $34 \quad 113$

mean(cats.pred $==$ test 1 \$pun.f)

[1] 0.7700565

C.2.2. Predictions on the Testing dataset

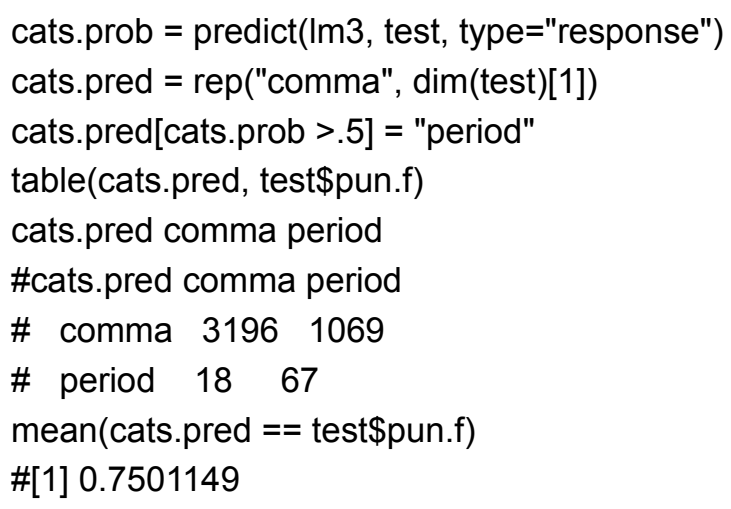

\section{Validity of the logistic regression model}

We use three methods, namely, receiver operating characteristic (ROC), k-fold cross-validation, and bootstrap cross-validation, to verify the validity of the logistic regression model we adopted.

ROC explains the model's performance by evaluating Sensitivity vs. Specificity. The area under the ROC curve is an index of accuracy: the higher the area under the curve, the better the prediction power of the model. As shown in Figure 1, the ROC for our logistic regression model is approximately 85.3\%, indicating a high level of validity of our model. 


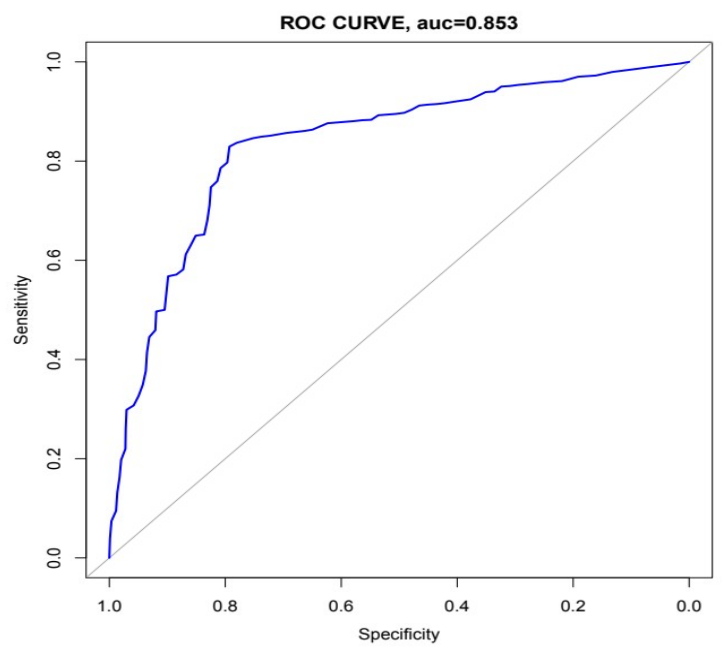

Figure 1: ROC curve of our model in the training data.

K-fold cross-validation can be used to assess how well a model performs in predicting the target variable on different subsets of the data. This technique partitions the data into $\mathrm{k}$ equally sized segments (called 'folds'). One fold is held out for validation while the other k-1 folds are used to train the model. This process is repeated $\mathrm{k}$ times, and the performance of each model in predicting the holdout set is tracked using a performance metric. The most common variation of cross validation is 10-fold cross-validation. The measures of R-squared, Root Mean Squared Error (RMSE), and Mean Absolute Error (MAE) are commonly used to measure the regression model performance in cross-validation. Rsquared represents the squared correlation between the observed outcome values and the predicted values by the model. The higher the adjusted R2, the better the model. RMSE measures the average prediction error made by the model in predicting the outcome of an observation, i.e., the average difference between the observed known outcome values and the values predicted by the model. The lower the RMSE, the better the model. MAE is an alternative to RMSE that is less sensitive to outliers. It corresponds to the average absolute difference between the observed and predicted outcomes. The lower the MAE, the better the model.

We repeated the 10-fold cross validation procedure five times. The mean error from the five repetitions was taken to be the final model error. The code used for this procedure and the results produced by the code are provided in the following.

\#\#\#

library(caret) 
set.seed(1234)

train_control <- trainControl(method="repeatedcv", number=5,repeats $=5$ )

model_fit <- train(Punctuation TopicShift + CategoryShift + CharacterShift +TimeShift + SpaceShift + factor(SemRel) + ExplicitMarker +Length, data=train, trControl=train_control, method="glm",family="binomial", na.action=na.exclude)

print(model_fit)

\#Generalized Linear Model

\#7078 samples

\#8 predictor

\#No pre-processing

\#Resampling: Cross-Validated (10 fold, repeated 1 times)

\#Summary of sample sizes: 4919, 4919, 4920, 4920, 4919, 4919, ...

\#Resampling results:

\section{\# RMSE $\quad$ Rsquared $\mathrm{MAE}$}

\# $0.3471815 \quad 0.2709448 \quad 0.2444051$

The bootstrap cross-validation process takes random samples from the dataset with re-selection and evaluates the model. The code used for this process is provided in the following.

train_control <- trainControl(method="boot", number=10)

model_fit2 <- train(Punctuation TopicShift + CategoryShift + CharacterShift +TimeShift + SpaceShift + factor(SemRel) + ExplicitMarker +Length, data=train, trControl=train_control, method="glm",family="binomial", na.action=na.exclude)

print(model_fit2)

\#Generalized Linear Model

\#7078 samples

\#8 predictor

\#No pre-processing

\#Resampling: Bootstrapped (10 reps)

\#Summary of sample sizes: $5466,5466,5466,5466,5466,5466, \ldots$

\#Resampling results:

\# RMSE $\quad$ Rsquared $\mathrm{MAE}$

$\begin{array}{lll}\# 0.3477411 & 0.2680985 & 0.2435315\end{array}$

As mentioned above, we mainly look at RMSE and MAE in evaluating model validity. RMSE and MAE in both tests are smaller than 0.5, indicating a high level of validity of our logistic regression model. 